\title{
Lesões Precursoras do Câncer Cervicouterino Associado ao Tabagismo: um Estudo sobre o Conhecimento entre as Mulheres que Fumam
}

\author{
Cervical-Uterine Precursor Lesion Associated to Tobacco Smoking: A Study \\ about the Knowledge among Women who Smoke \\ Lesiones Precursoras del Cáncer Cervical Uterino Asociado al Tabaquismo: un \\ Estudio sobre el Conocimiento entre Mujeres que Fuman
}

\author{
Maria Cristina de Melo Pessanha Carvalho', Carmen Lucia de Paula ${ }^{2}$, Ana Beatriz Azevedo Queiroz ${ }^{3}$
}

\begin{abstract}
Resumo
Introdução: Acredita-se que uma das possibilidades para alcançar resultados de modo a favorecer a saúde da população feminina em relação à alta incidência de câncer cervicouterino seja a construção de estratégias para prevenção dos fatores de risco, entre eles o tabagismo. Objetivo: Discutir a associação das lesôes precursoras do câncer cervicouterino com o tabagismo evidenciado na fala de mulheres portadoras dessas alteraçôes cervicais. Método: Pesquisa qualitativa, do tipo descritiva, realizada em uma Instituição Pública Federal no Município do Rio de Janeiro. Participaram 40 mulheres com o diagnóstico de lesáo precursora do câncer cervicouterino, divididas em 22 tabagistas e 18 com história pregressa de tabagismo entre a faixa etária de 22 e 70 anos. Os dados foram coletados por meio de entrevistas semiestruturadas, e analisados sob a perspectiva da Teoria das Representaçôes Sociais, sendo categorizadas de acordo com a Temática de Bardin. Resultados: Na fala das mulheres, percebe-se a associação do ato de fumar ao longo de suas vidas com o desenvolvimento das lesões precursoras do câncer cervicouterino, sendo destacadas quatro categorias: a relação da doença com o tabaco, o cigarro; a doença e a tentativa de mudança de estilo de vida; a força da mídia, contribuindo no processo de informação; e a culpa por manter o tabagismo. Conclusão: Nota-se a necessidade de ações estratégicas baseadas no universo consensual dessas mulheres, contribuindo para a importância do combate ao tabagismo como um fator de risco evitável para o desenvolvimento do câncer cervicouterino.
\end{abstract}

Palavras-chave: Tabagismo; Neoplasia Intra-Epitelial Cervical; Saúde da Mulher

Recorte de Dissertação de Mestrado Apresentada ao Programa de Pós-Graduação da Escola de Enfermagem Anna Nery da Universidade federal do Rio de Janeiro (EEAN/UFRJ/2008).

${ }^{1}$ Doutoranda em Enfermagem pelo Programa de Pós-Graduação da EEAN/UFRJ. Especialista em Enfermagem Oncológica. Enfermeira do Hospital Federal de Ipanema e CMS Píndaro de Carvalho Rodrigues. Rio de Janeiro. Brasil. E-mail: mcrismelo4@hotmail.com.

${ }^{2}$ Enfermeira. Mestre em Enfermagem pela Universidade do Estado do Rio de Janeiro (UERJ). Enfermeira do Ambulatório de Oncologia do Instituto Nacional de Câncer (INCA)/Hospital do Câncer II (HC II)/MS. Professora Colaboradora do Programa de Pós-Graduação da Universidade Gama Filho (Enfermagem em Centro Cirúrgico e Central de Material Esterilizado).E-mail: carmenpaula@ymail.com.

${ }^{3}$ Enfermeira. Doutora em Enfermagem. Professora Adjunta do Departamento de Enfermagem Materno-Infantil da UFRJ. Coordenadora da Residência Multiprofissional em Saúde da Mulher do Hospital Escola São Francisco de Assis da UFRJ, Brasil. E-mail: anabqueiroz@oi.com.br.

Enderȩ̧o para correspondência: Carmen Lúcia de Paula. Rua Jaracatiá, 174/103. Irajá, CEP: 21235-570 Rio de janeiro (RJ), Brasil. 


\section{INTRODUÇÃO}

No Brasil, o câncer do colo do útero é considerado um problema de Saúde Pública, visto que é a neoplasia de maior incidência e mortalidade entre as mulheres. De acordo com as estimativas do Instituto Nacional de Câncer (INCA), para o ano de 2010 e 2011, são esperados 18 mil novos casos, sendo esse tipo de tumor o segundo mais frequente e a quarta causa de morte na população feminina por câncer no Brasil ${ }^{1}$.

Atualmente, $44 \%$ dos casos da patologia em questão são provenientes de lesôes precursoras do câncer do colo uterino (LPCCU), chamada de carcinoma in situ ${ }^{1}$. Essas lesōes destacam-se pela presença de modificaçóes do epitélio original, constituindo as manifestaçóes pré-cancerosas que podem evoluir para o câncer cervicouterino ${ }^{2-3}$.

O câncer do colo do útero, tido como invasor, evolui a partir da neoplasia intraepitelial cervical I (NIC I), porém nem toda NIC evoluirá para uma doença invasora. No entanto, ressalta-se que todas as NIC devem ser consideradas como lesôes significativas e, como tal, devem ser tratadas e acompanhadas, pois mulheres diagnosticadas precocemente e tratadas adequadamente têm a possibilidade de $100 \%$ de cura ${ }^{4}$.

Vale destacar que o principal fator de risco para causar esse tipo de câncer é a infecção pelo papilomavírus humano, o HPV, sendo que esse vírus apresenta alguns subtipos oncogênicos, que estão relacionados a tumores malignos, tais como os subtipos virais 16 e $18^{1}$.

Todavia, vale ressaltar que menos de $1 \%$ das mulheres com infecção por HPV de risco oncogênico irão desenvolver câncer do colo uterino, porém esse risco se potencializa quando a infecção viral é associada ao tabagismo, destacando assim que o uso frequente do cigarro é uma causa comprovada da evoluçáo dessa patologia 5 .

O tabaco diminui significativamente a quantidade da função das células de Langherans, que são responsáveis pela defesa do tecido epitelial, além do que o cigarro contém mais de 300 substâncias cancerígenas ${ }^{6}$.

Cabe ressaltar que o número de fumantes, entre o sexo feminino, tem aumentado em todo mundo, influenciado por inúmeros fatores econômicos e socioculturais, principalmente em países em desenvolvimento, transformando o tabaco em uma das maiores causas desse tipo de tumor ${ }^{7}$. Corroborando esse fato, um estudo que abordou as alteraçóes citopatológicas e fatores de risco ilustrou que $48 \%$ de um total de 65 mulheres que apresentavam alteraçóes cervicais eram tabagistas ${ }^{8}$.

Dessa forma, a problemática desse estudo emergiu da prática de atendimento às mulheres portadoras de LPCCU quando se identificou, empiricamente, que algumas delas faziam referência do tabagismo com a situação vivida; no entanto, outros segmentos além de não o fazerem, por vezes, não acreditavam existir qualquer ligação entre essas variáveis.

Esse fato refletiu nas diferentes formas de se pensar e agir frente à vivência da alteração cervical e ao tabagismo, que são permeadas de regras sociais estabelecidas no meio cultural e que se subjetivam e individualizam em cada pessoa.

Acredita-se que uma das possibilidades para alcançar resultados diferentes, de modo a favorecer a saúde da população feminina contra o desenvolvimento do câncer cervicouterino, seja a construção de estratégias para prevenção dos fatores de risco evitáveis, como o tabagismo; porém, estratégias que levem em consideração os aspectos psicossociais que estáo envolvidos nesse fenômeno, e não apenas condicionantes informativos ou prescritivos.

A prevenção e o controle do câncer do colo do útero estấo entre os mais importantes desafios científicos e de Saúde Pública da nossa época, que deve perpassar tanto pelo uso do preservativo em todas as relaçôes sexuais, mas também pelo combate ao tabagismo feminino.

A necessidade de revisão, elaboraçáo e novas abordagens nos diversos níveis de atuação em saúde deve ser vista como prioritária na luta contra o fumo, no sentido de mobilizar não só os profissionais para trabalhar de forma efetiva, mas a própria população.

Sob essa ótica, o presente estudo tem como objetivo discutir a associação das LPCCU com o tabagismo evidenciado na fala de mulheres portadoras dessas alteraçôes cervicais.

\section{MÉTODO}

Trata-se de um estudo com abordagem qualitativa e tipologia descritiva, devido à investigação exigir um entendimento aprofundado da realidade vivida por essas mulheres.

Diante da problemática descrita, para dar suporte à interpretaçáo e à subjetividade dos dados produzidos pelos sujeitos do estudo, utilizou-se, como referencial teórico, a Teoria das Representaçôes Sociais, que oferece subsídios para embasar abordagens culturais, valores e crenças desse grupo feminino. Entende-se, por essa teoria, aquela que estuda o pensamento comum, popular e ingênuo das pessoas sobre uma determinada coisa ou acontecimento, levando o indivíduo a agir de acordo com aquilo que ele pensa $^{9-10}$.

A pesquisa foi realizada em uma Instituição Pública Federal no Município do Rio de Janeiro, local destacado como referência em atendimento à patologia cervical. Esse Serviço recebe mulheres oriundas de Unidades Básicas de Saúde para tratamento das alteraçôes cervicais.

A pesquisa foi composta por 40 sujeitos, divididos em dois grupos: um grupo com 22 mulheres tabagistas e 
outro com 18 mulheres apresentando história pregressa de tabagismo.

Os critérios de inclusão foram: ter diagnóstico de LPCCU comprovado mediante resultados de exames colpocitológicos e/ou colposcópicos; estar em tratamento na instituição referida; autodeclaração de ser tabagista ou com história pregressa de tabagismo e aceitar participar do referido estudo.

Como critérios de exclusão, foram delimitadas mulheres que não se declararam tabagistas, mesmo fumando de um a três cigarros por dia, e aquelas que estavam em processo de confirmação de diagnóstico.

Os dados foram coletados no período de fevereiro a junho de 2008, por meio de entrevistas semiestruturadas, tendo a necessidade de compreensão dos conteúdos que circulam nos diferentes tempos como interação, hábito e imaginário social.

Destaca-se que a coleta de dados num estudo de representação social exige longas entrevistas semiestruturadas. Assim, obteve-se uma média de 30 a 45 minutos por entrevista ${ }^{11}$. Utilizou-se gravador portátil mediante fitas magnéticas para gravar as falas com a prévia autorização das entrevistadas.

A entrevista apresentou um roteiro com perguntas abertas que tinham o propósito de explorar os principais discursos e falas das depoentes acerca dos fatores causais das LPCCU e sua relação com o tabagismo, e elucidar as percepçóes de mundo do respondente, observando, avaliando e compreendendo o fenômeno do conhecimento comum.

As entrevistas foram realizadas em uma sala reservada após a consulta médica e com prévio agendamento, respeitando, assim, a disponibilidade das depoentes. Posteriormente, os dados foram transcritos a fim de facilitar a etapa da análise.

Com relação aos aspectos éticos, foram seguidas as recomendaçóes da Resolução no 196/96, que trata das normas de pesquisa envolvendo seres humanos. Os participantes assinaram o Termo de Consentimento Livre e Esclarecido, constando o objetivo da pesquisa, a garantia do anonimato e o sigilo de informaçôes prestadas.

A pesquisa foi aprovada pelo Comitê de Ética da Escola de Enfermagem Anna Nery/Hospital Escola São Francisco de Assis/Universidade Federal do Rio de Janeiro sob o número de Protocolo n ${ }^{\circ}$ 02/2008.

Para a organizaçáo dos dados, as fitas foram transcritas e ocorreram leituras flutuantes. Após leituras exaustivas de todo o material, classificou-se em temas que estruturaram as categorias empíricas para análise, segundo orientação da Temática de Bardin ${ }^{12}$. A categoria é um sistema de classificação de elementos constitutivos de um conjunto por diferenciação agrupado em categorias temáticas ${ }^{12}$.

Frente a essa ótica, as categorias foram agrupadas por liames que ilustraram a correlação da alteração cervical com o tabagismo. E, por fim, os dados foram analisados sob a perspectiva psicossocial da Teoria das Representaçóes Sociais.

\section{RESULTADOS E DISCUSSÃO}

As categorias apontaram para a relação que as entrevistadas fizeram do tabagismo com os resultados da citologia e mudança na vida da mulher após tomar conhecimento do resultado do exame.

Emergiram, portanto, quatro categorias que foram denominadas: 1) A relação da doença com o tabaco; 2) $O$ cigarro, a doença e a tentativa de mudança de estilo de vida; 3) A força da mídia contribuindo no processo de informação; e 4) A culpa por manter o tabagismo.

\section{A RELAÇÃO DA DOENÇA COM O TABACO}

Nesta categoria, analisou-se a relação que os sujeitos fizeram entre as alteraçôes cervicais vividas e o tabagismo. Das 40 entrevistadas, 35 reconheciam haver algum tipo de associação entre a alteração cervical e o tabagismo. No entanto, o valor ou o peso dessa associação apresentou-se bastante diversificada, sendo que nenhuma atribuiu o cigarro como causador efetivo das LPCCU.

Sempre ouvi falar que o cigarro faz mal, causa câncer! Sei lá. Eu sempre fumei fumo mais ou menos dez cigarros por dia, sempre quis largar [...]. Porque já era pra ter largado, porque eu nunca deixei de (pausa). Ah sei lá. Eu sempre estou nos hospitais. Sempre eu fiz preventivo, só dava negativo. Eu fico pensando assim: será que meu parceiro está com alguma doença, passou pra mim. Eu fico com isso na minha cabeça. Mas é lógico que o cigarro só piora o problema.

(Depoente no 16 - 48 anos - tabagista há 16 anos - NIC I)

Eu não sei explicar, pode ser que o cigarro tenha ajudado, piorado a situaçáo. Mas foi do meu marido. Eu não meto a mão no fogo por ele. Acho que é por ele sim. Eu sei que o cigarro ajudou, mas quem transmitiu foi pelo meu marido.

(Depoente no 31 - 58 anos - ex-tabagista - NIC III)

Eu acho que é do cigarro, porque o cigarro vai fazendo mal, dando doença, até câncer. Mas eu fumo há muito tempo, nunca parei, mas vou tentar agora. Mas na verdade acho que é do sexo, porque o homem nunca faz tratamento, aí devido, do que eles joga na gente, que deve causar alguma lesão, pra causar na mulher, eu acho que a secreção dele causa esse negócio na gente. Eu acho que é do sexo em primeiro lugar e depois do cigarro. E é lógico que para quem fuma tudo é pior, a cura, o tratamento é mais difícil.

(Depoente no 9 - 51 anos - Tabagista há 8 anos - NIC III) 
Nesta categoria ficou clara que a maioria das entrevistadas ancora a origem do problema na relação sexual na traição vinda do parceiro e não ao tabagismo. Este, por sua vez, foi representado como um fator contribuinte para o desenvolvimento da doença, podendo inclusive causar câncer.

Observa-se que as mesmas têm noção de que o tabaco é prejudicial à sua saúde, e por isso se percebem mais vulneráveis às consequências graves, por fumarem, do que aquelas mulheres que não são tabagistas.

Os diversos aspectos da associaçáo do fumo com as alteraçôes celulares cervicais vividas são na verdade oriundos do que circulam em seu cotidiano, na mídia e, até mesmo, no universo hospitalar em que estão inseridas pelo tratamento realizado.

Isto influencia na maneira de pensar, não só no meio como adquiriram o problema, mas principalmente no enfrentamento e tomada de decisóes, como parar de fumar ou não. Diante desses fatos, a maioria das pessoas interpreta o que lhes acontece, forma uma opinião sobre a própria conduta ou a de familiares/pessoas e orienta suas açôes em conformidade com essa interpretaçáo ${ }^{9}$.

Em contrapartida, houve um pequeno segmento de entrevistadas que não acreditam existir qualquer relação entre a situação vivida e o tabagismo, questionando a real existência da negatividade do fumo com esse problema. Veja o depoimento abaixo:

Sei lá. Não sei, será que é por causa do cigarro? Eu questiono muito [...]. Para mim o cigarro não tem ligação nenhuma com isso. Esse negócio é coisa que a mulher pega e fumar não tem nada a ver. Por isso, não largo o meu cigarro. Tenho que cuidar de outro jeito.

(Depoente no 17 - 32 anos-Tabagista há 17 anos - NIC II)

Enfatiza-se a posição de Moscovici ${ }^{9}$ com relação aos indivíduos agirem em função de suas orientaçôes e interpretaçôes, ou seja, se o cigarro para esse grupo de entrevistadas não é representado como um dos causadores ou potencializadores das LPCCU, a decisão de querer enfrentar e largar o fumo também não será algo prioritário em sua vida, nem mesmo fará parte de seus planos.

\section{CIGARRO, A DOENÇA E A TENTATIVA DE MUDANÇA DE ESTILO DE VIDA}

Esta categoria deixa clara a tentativa de mudança de estilo de vida quando se descobre o diagnóstico das LPCCU e, entre essas tentativas, está a possibilidade de não continuar sendo tabagista.

O reconhecimento do fumo, como um fator de desenvolvimento das alteraçóes cervicais, causa desconforto emocional, e contribui de forma significativa para o desenvolvimento do câncer cervicouterino.
Sendo o fumo considerado no universo reificado das ciências como o principal fator de risco para o desenvolvimento dos cânceres, por possuir mais de 67 substâncias cancerígenas, aumentando o risco de aparecimento dessa doença em até 15 vezes ${ }^{13}$, é compreensível que haja uma transferência da forma hegemônica para o universo consensual, influenciando, assim, no entendimento social do malefício do tabaco para os indivíduos.

Historicamente, as mulheres passaram a fumar como uma ascensão social e de igualdade de gênero. No entanto, a relação do uso do cigarro com as mulheres na atualidade é conflitante, carreada de transtornos emocionais, devido ao fato de as mesmas geralmente fumarem em resposta a situaçóes negativas de vida, situaçôes de estresse e na perspectiva de moderar a desmotivaçáo em viver ${ }^{14}$.

Porém, quando se veem frente a situações de perigo de vida, ou medo do agravamento da doença ou até mesmo da morte, como é o caso do câncer, que ainda hoje é carreado de ideias que fazem parte do senso comum, compartilhadas em um meio social, onde informaçóes que circulam e se cristalizam de finitude aparecem como motivadores para deixar o cigarro.

Algumas mulheres veem a necessidade de mudar de costumes, principalmente deixando de lado hábitos nocivos, como o de fumar, beber, comer inadequadamente. Vale destacar que, quando se trata da própria saúde, se estabelece um resultado social de construção de padróes de conforto para a sua saúde ${ }^{15}$. Isto pode ser identificado no seguinte depoimento:

Fumar, ainda não consegui parar de fumar. Já tentei, mas não consegui ainda. Em me alimentar, venho me alimentando melhor. Venho comendo certas coisas que antigamente eu não comia, muita fruta, muitos legumes. A gente escuta, que a couve-flor é muito bom para o útero, entáo eu como bastante couve-flor, a minha higiene agora é mais rigorosa, isso tudo mudou pra caramba. A única coisa que eu não consegui largar foi o cigarro, mas vou tentar. (Depoente no 23 - 32 anos - Tabagista há 15 anos NIC II /NIC III)

As práticas de mudança de hábito são orientadas por uma lógica que resulta de experiência social ${ }^{16}$. Diante dessa afirmação, essas mulheres tentam produzir ações que irão reestabelecer a sua saúde, reconhecendo a necessidade de modificarem o seu modo de pensar e agir em relação ao seu bem-estar e ao seu corpo.

$O$ papel que a representação tem em orientar as práticas do indivíduo permite compreender porque alguns problemas se sobressaem numa sociedade ${ }^{17}$. Neste caso, quanto às mulheres portadoras de LPCCU, suscitam decisôes, tais como: aderir ao abandono do tabaco e mudar de estilo de vida, que são eventos que se inserem 
no papel de orientação das representaçóes acerca dessas lesôes e que foram construídas e elaboradas pelo meio social em que convivem.

\section{A FORÇA DA MÍDIA CONTRIBUINDO NO PROCESSO DE INFORMAÇÃO}

A mídia exerce influência no comportamento e estilo de vida das pessoas que, muitas vezes, idealizam viver o que o personagem ou um produto mostram: ser agradável, bonito, interessante e prazeroso. A busca pela aceitação na sociedade e, muitas vezes, autoafirmação, pode levar as pessoas a adquirem hábitos sem um questionamento prévio sobre prejuízos que podem causar, inclusive danos à saúde. Foi assim que, durante muitos anos, o cigarro teve uma forte propaganda nos meios de comunicação, como uma fonte de glamour e charme, ganhando muito de sua força inclusive entre o grupo feminino. A indústria do tabaco passava, através do marketing, que fumar era sinônimo de momentos de prazer e aventura, sendo que isso compensava qualquer possibilidade de riscos à saúde, pois as condiçôes socioeconômicas e culturais também interferem na aquisição e manutenção do tabagismo. Diante desse quadro, percebe-se que a associação entre o ato de fumar e um estilo de vida aventureiro e de sedução é comum na propaganda do cigarro ${ }^{18}$.

Atualmente, encontra-se um forte movimento contra a tradição cultural positiva do tabaco, tais como as leis estaduais e municipais contra o fumo em determinados locais, assim como: esforços do Ministério da Saúde (MS) contra a propaganda e incentivo ao consumo do tabaco. Frente a esse cenário, torna-se evidente que as açôes para controle do tabagismo dependam da articulaçáo de diferentes tipos de estratégias, tanto nos setores sociais, governamentais e não governamentais ${ }^{19}$.

Desta forma, a referência que se tem do cuidado é voltada para o discurso da mídia, evidenciando a valorizaçáo da saúde, sem tabaco, dentro de um circuito de comunicação. Deve-se também ressaltar a contribuição de um maior acesso da população às informaçôes, conhecimento sobre a doença e prevençáo acerca dos fatores de risco para o câncer cervicouterino.

O papel dos meios de comunicação, principalmente a televisão, é relevante na construção da subjetividade e do senso comum, influenciando na transformação dos hábitos, como o tabagismo e a prevençấo do câncer cervical ${ }^{20}$. Representaçôes estas que apresentam influência direta do que se ouve falar sobre o problema, seja na mídia, no meio social em que se vive, ou pelo próprio discurso médico. Dessa maneira, algumas mulheres do presente estudo apreendem tais informaçóes e tentam deixar o tabagismo.

No entanto, sabe-se que parar de fumar não depende somente da informaçáo sobre os seus malefícios do cigarro.
Existem outros fatores que estáo envolvidos, como a dependência, a força de vontade, o tratamento contínuo, o acesso aos serviços de saúde; mas como se destaca no depoimento abaixo, sem dúvida, o conhecimento nos parece ser o primeiro passo:

Eu fumava 10 cigarros por dia, aí eu comecei a ouvir na televisão dizendo que fumar não é bom, que traz problemas. Mas só larguei depois que comecei a sentir cansada, e o médico dizia larga isso, mulher, deixa de fumar, senão vai ficar pior. Eu larguei, depois de 15 anos e aí logo apareceu isso, essa doença. Na televisão eu ouvi a propaganda falando que até essa palavra me conformou muito. A moça na propaganda falava assim: "Olha essa doença é perigosa, mas é para a pessoa que não se cuida. Enquanto é uma coisinha pouca, e a pessoa se cuidar, aquilo ali não tem pra onde ir". Ela falou essa palavra na televisão, aí eu pensei, tenho que me cuidar e parar de fumar. Foi difícil, mas eu consegui. Graças a Deus!

(Depoente no 14 - 62 anos - ex-tabagista - NIC III/ carcinoma in situ)

Adicionado a esse fato, pode-se ainda citar a forte presença da mídia televisiva como fonte de informaçôes, sem contar o círculo de amizades, que, sem dúvida, contribuíram para a formação das representações sociais das LPCCU pelas mulheres que utilizam tabaco. Dessa forma, pode-se compreender como os saberes sociais se constroem; pois trata-se de saber vinculado ao contexto de uma relação com o meio social em que se vive.

Neste caso, os meios de comunicação fornecem discursos e informaçôes com ideias diferentes e acrescentadas a informaçôes do seu meio social, ou seja, das pessoas que a cercam. As mulheres vão construindo e organizando suas representações sobre esse fenômeno. Tais representaçôes são elaboraçôes formadas a partir das informaçôes que circulam que se renovam e se cristalizam? ${ }^{9}$ Dessa maneira, as mulheres do presente estudo se apropriam das informações, tentando colocá-las em prática e deixar de fumar.

\section{A CULPA POR MANTER O TABAGISMO}

Destarte, a difícil tarefa de parar de fumar envolve sentimentos de fracasso, desânimo e de culpa por não conseguir alcançar o seu objetivo, principalmente quando se reconhece que esse fator é prejudicial ao problema de saúde que é vivenciado.

Nesta categoria, foi possível identificar essa visão de culpabilidade frente ao diagnóstico presente e o que o uso do tabaco contínuo pode provocar futuramente. O processo de culpa desenvolveu-se através de atitudes não tomadas, dos cuidados que não foram praticados $\mathrm{e}$ 
hábitos que não foram abolidos, tais como o fumo, como um meio de prevençáo do câncer do colo uterino. Segue abaixo o depoimento:

Porque eu sou relaxada, porque eu não fazia preventivo, eu náo larguei do cigarro, eu fumo um maço por dia, tentei diminuir, mas não deu. É vício. Fico deprimida quando náo fumo. Ficava com o pé no chão, de barriga molhada, não tinha aqueles cuidados, porque a mulher é sensível, ela tem que ter os seus cuidados, por exemplo, se você cai e machuca, se você não colocar remédio ali, vai ficar uma ferida, vai infeccionar, vai dar até uma doença, mesma coisa, o cigarro, se você sabe que aquilo não é bom e continua, vai aparecer problemas. E a inflamação do colo do útero é assim, começa assim, de um grãozinho de areia, aquilo vai aumentando. Eu acho que fiquei assim por isso, de não ter cuidado da minha saúde, de não parar de fumar, de não ir ao médico de seis em seis meses, acho assim. Já tentei parar, mas é muito difícil, eu não sei como para de fumar [...].

(Depoente no 27 - 31 anos - Tabagista há 5 anos NIC III/ carcinoma in situ)

Sabe-se que, para qualquer tratamento de saúde, a subjetividade humana, os desejos, os limites do corpo e da mente estão presentes e devem ser levados em consideraçáo, pois o ser humano não é uma máquina que apenas obedece a ordens sem julgamentos, interpretaçôes e representaçóes. $\mathrm{E}$, quando se trata do tabagismo, existem diversas barreiras difíceis de transpor para deixar de fumar, como: síndrome de abstinência, depressão, ansiedade e falta de concentração. De cerca de $80 \%$ dos fumantes que desejam parar de fumar, apenas $3 \%$ conseguem sem ajuda ${ }^{21}$.

Portanto, faz-se necessário o apoio da equipe multidisciplinar junto a essas mulheres, estimulando ao abandono do tabagismo. Sendo assim, é de suma importância que se tenha em mente a preocupação em aproximar-nos desse espaço, para que se possa melhor orientar e intervir na decisão dessas mulheres. Torna-se relevante ter práticas de intervenção, o que modificará as condutas dos sujeitos para revisão de suas práticas de cuidado e prevenção conforme referência de Jodelet acerca da intervenção ${ }^{22}$.

\section{CONCLUSÃO}

Conclui-se que os resultados deste estudo mostraram que as mulheres acreditam na associação do tabagismo com o desenvolvimento das lesóes precursoras do câncer cervicouterino e que esse fator certamente poderia ter sido evitado.

Percebe-se que as mulheres reconhecem e entendem que o tabaco é prejudicial à saúde; no entanto, as falas ilustram a subjetividade dessa população feminina acerca do tabaco e o conflito que se vivencia diante da necessidade de abandonar o tabagismo.

A relação da doença com o fumo foi evidente no discurso dessas mulheres, o que ilustra o forte predomínio sociocultural ancorado na relação entre mulher e tabaco. Sentimentos de fuga, incertezas, dúvidas e questionamentos fazem parte da subjetividade dessa população feminina mediante as representaçóes sociais construídas.

A relevância do estudo consiste em contribuir para a identificação de questôes psicossociais que interferem nas atitudes relacionadas ao abandono do cigarro. Muitas mulheres revelaram que não conseguiam deixar o fumo, mesmo reconhecendo ser prejudicial à sua saúde.

Neste sentido, é imprescindível que haja reforços e inovaçóes em programas voltados para a não adesão ao tabagismo, além de enfatizar esclarecimentos quanto aos malefícios do seu uso. Possibilita-se a utilizaçáo de abordagens que, em nível de seus preceitos e crenças, devam ser entendidas pela equipe multidisciplinar. Considerando que náo deve ser valorizado apenas um contexto técnico-científico e sim o contexto psicossocial, histórico e cultural dessas mulheres.

O estudo criou subsídios na busca de conhecimento das representaçóes das mulheres que fumam, indicando uma ferramenta inovadora em nossa prática profissional diária, além de possibilitar o desenvolvimento de novas estratégias, pois acredita-se que, diante das representaçóes das mulheres que fumam e que são portadoras de lesóes precursoras, será possível elaborar intervençóes de grande impacto à náo adesão ao tabaco pela populaçáo feminina.

\section{CONTRIBUIÇÕES}

Maria Cristina de Melo Pessanha Carvalho e Carmen Lúcia de Paula contribuíram na concepção e planejamento do projeto de pesquisa, na obtenção e/ou análise e interpretação dos dados e na redação e revisão crítica; Ana Beatriz Azevedo Queiroz contribuiu na obtenção e/ou análise e interpretação dos dados e na redação e revisão crítica.

\section{Declaraçáo de Conflito de Interesses: Nada a Declarar.}

\section{REFERÊNCIAS}

1. Instituto Nacional de Câncer (Brasil). Estimativa 2010: incidência de câncer no Brasil [Internet]. Rio de Janeiro: INCA; c2009 [citado 2011 mar 11]. 98 p. Disponível em: http://www1.inca.gov.br/ estimativa/2010/estimativa20091201.pdf

2. Longatto Filho A, Etlinger D, Gomes NS, Cruz SV, Cavalieri MJ. Frequiência de esfregaços cérvico-vaginais 
anormais em adolescentes e adultas: revisão de 308.630 casos. Rev Inst Adolfo Lutz. 2003;62(1):31-4.

3. Bosch FX, You-Lin Q, Castellsagué X. The epidemioly of human papilomavirus infection and its association with cervical cancer. Int J Gynaecol Obstet. 2006;94(supp. 1):s8-21.

4. Instituto Nacional de Câncer (Brasil). Coordenação de Prevenção e Vigilância. Nomenclatura brasileira para laudos cervicais e condutas preconizadas: recomendaçōes para profissionais de saúde. Rio de Janeiro: INCA; 2006.

5. Coker AL, De Simone C, Eggleston KS, Hopenhayn C, Nee J, Tucker T. Smoking and survival among Kentucky women diagnosed with invasive cervical cancer: 19952005. Gynecol Oncol. 2009 Feb;112(2):365-9.

6. Queiroz AMA, Cano MAT, Zaia JE. O papiloma vírus humano (HPV) em mulheres atendidas pelo SUS na cidade de Patos de Minas - MG. Rev Bras Anal Clín. 2007; 39(2):151-7.

7. Horta RL, Horta BL, Pinheiro RT, Morales B, Srey MN. Tabaco, álcool e outras drogas entre adolescentes em Pelotas, Rio Grande do Sul, Brasil: uma perspectiva de gênero. Cad Saúde Pública. 2007;23(4):775-83.

8. Melo SCCS, Prates L, Carvalho MDB, Marcon SS, Pelloso SM. Alterações cito patológicas e fatores de risco para a ocorrência do câncer de colo uterino. Rev Gaúcha Enferm. 2009;30(4):602-8.

9. Moscovici S. Representaçôes sociais: investigações em psicologia social. 4a ed. Petrópolis: Vozes; 2003.

10. Jodelet D, organizadora. As representaçôes sociais. Ulup L, tradutora. Rio de Janeiro: EdUERJ; 2001. Representaçôes sociais: um domínio em expansão; p. 31-61.

11. Spink MJ. Desvendando as teorias implícitas: uma metodologia de análise das representaçôes sociais. In: Moscovici S, org. Representações sociais: investigações em psicologia social. Petrópolis: Vozes; 2003.

12. Bardin L. Análise de conteúdo. Lisboa: Ediçôes 70; 2010.
13. Pinheiro SMS, Cardoso JP, Prado FO. Conhecimentos e diagnóstico em câncer bucal entre profissionais de odontologia de Jequié, Bahia. Rev Bras Cancerol. 2010; 56(2):195-205.

14. Eckerdt NS, Corradi-Webster CM. Sentidos sobre o hábito de fumar para mulheres participantes de grupo de tabagistas. Rev Latino-Am Enfermagem. 2010;18(n. espec):641-7.

15. Minayo MCS, Hartz ZMA, Buss PM. Qualidade de vida e saúde: um debate necessário. Ciênc saúde colet. 2000;5(1):7-18.

16. Ferreira J. Cuidado do corpo em vila de classe popular. In: Duarte LFD, Leal OF, organizadores. Doença, sofrimento, perturbação: perspectivas etnográficas. Rio de Janeiro: Fiocruz; 2001.

17. Herzlich CA. Problemática da representação social e sua utilidade no campo da doença. Physis. 2005;15(supl):57-70.

18. Giacomini Filho G, Caprino MP. A propaganda de cigarro: eterno conflito entre público e privado. UNIrevista. 2006;3(1):1-13.

19. Cavalcante TM. O controle do tabagismo no Brasil: avanços e desafios. Rev psiquiatr clín. 2005;32(5):283-300.

20. Medina CB. Corpo-necessário no telejornal: representaçôes sociais sobre o corpo no discurso do risco. XXIX Congresso Brasileiro de Ciências da Comunicação INTERCOM; 6-9 set 2006; Brasília, BR. [local desconhecido: Intercom - Sociedade Brasileira de Estudos Interdisciplinares da Comunicação; 2006]. p. $1-15$.

21. Meirelles RHS, Gonçalves CMC. Abordagem cognitivocomportamental do fumante. Diretrizes para cessação do tabagismo. J bras pneumol. 2004;30(supl. 2):s30-5.

22. Jodelet D. Imbricações entre representações sociais e intervenção. In: Moreira ASPM, Camargo BV. Contribuiçóes para teoria e o método de estudos das representações sociais. João Pessoa: Ed. Universitária; 2007. 


\section{Abstract}

Introduction: It is believed that a possibility to achieve results so as to favor the female population health concerning the high incidence of cervical-uterine cancer is the design of strategies for the prevention of risk factors, like tobacco smoking. Objective: To discuss the association between cervical-uterine cancer precursor lesions and tobacco smoking evidenced in women's talk who have these cervical changes. Method: Qualitative and descriptive research, carried out in a Federal Public Institution in the city of Rio de Janeiro. 40 women who were diagnosed with cervical-uterine cancer precursor lesion participated, divided in 22 smokers and 18 women with past history in smoking within the age group from 22 to 70 . The data were collected by means of semi-structured interviews, and analyzed under the perspective of the Social Representation Theory and categorized according to Bardin's content analysis model. Results: In the women's talk, association between tobacco smoking throughout their lives and the development of cervical-uterine cancer precursor lesions is noticed, and 4 categories are highlighted: the relationship between the disease and tobacco, cigarettes; the disease and the attempt to change their life style; the media strength, contributing to the information process; the blame for keeping the tobacco smoking. Conclusion: It can be noticed the need of strategic actions based on the consensual universe of these women that contributes to the importance of fighting tobacco smoking as a preventable risk factor for developing cervical-uterine cancer.

Key words: Smoking; Cervical Intraepithelial Neoplasia; Women's Health

\section{Resumen}

Introducción: Se acredita que una de las posibilidades para alcanzar resultados de modo a favorecer a salud de la población femenina en relación a alta incidencia de cáncer cervical uterino, sea la construcción de estrategias para prevención de los factores de riesgo evitables, como el tabaquismo que entre otros, contribuye para el desarrollo del mismo. Objetivo: El objetivo de este estudio consiste en discutir la asociación de las lesiones precursoras del cáncer cervical uterino con el tabaquismo evidenciado en el habla de las mujeres. Método: La investigación es cualitativa, de tipo descriptivo, realizada en una Institución Pública Federal en el Municipio del Rio de Janeiro. Participaron 40 mujeres que tenían el diagnóstico de lesión precursora del cáncer cervical uterino, divididas en 22 tabaquistas y 18 mujeres con historia previa de tabaquismo entre la franja etaria de 22 y 70 ańos. Los datos fueron colectados por medio de entrevistas semiestructuradas, y analizados bajo la perspectiva de la Teoría de las Representaciones Sociales y se clasifican de acuerdo a la temática de Bardin. Resultados: En el habla de las mujeres se destaca la asociación del acto de fumar a lo largo de sus vidas con el desarrollo de las lesiones precursoras del cáncer cervical uterino, siendo destacadas 4 categorías: la relación de la enfermedad con el tabaco, el cigarrillo, enfermedad y la tentativa de mudanza de estilo de vida; la fuerza de los medios de comunicación contribuyendo en el proceso de información; la culpa por mantener el tabaquismo. Conclusión: En este aspecto, se observa que la necesidad de acciones estratégicas basadas en el universo consensual de estas mujeres contribuye a la importancia de la lucha contra el tabaquismo como factor de riesgo evitable para el desarrollo de cáncer de cervical uterino.

Palabras clave: Tabaquismo; Neoplasia Intraepitelial del Cuello Uterino; Salud de la Mujer 